\title{
Does Brand Equity Affect Patient Loyalty to The Hospital?
}

\author{
Apakah Ekuitas Merek Mempengaruhi Kesetiaan Kunjungan Pasien \\ Pada Rumah Sakit
}

\author{
Yoridha A. Sinuraya ${ }^{1}$, Ermi Girsang ${ }^{2}$, Ali N. Nasution ${ }^{3}$, Putranto Manalu ${ }^{* 4}$, Ulina Karokaro ${ }^{5}$ \\ ${ }^{1,3}$ Bagian Kedokteran, Universitas Prima Indonesia, Medan \\ $2,4,5$ Bagian Kesehatan Masyarakat, Universitas Prima Indonesia, Medan
}

DOI: 10.24252/al-sihah.v13i1.21130

Received: 20 May 2021 / In Reviewed: 5 June 2021 / Accepted: 28 June 2021 / Available online: 30 June 2021

(C)The Authors 2021. This is an open access article under the CC BY-NC-SA 4.0 license

\begin{abstract}
The rapid growth of hospitals creates conditions that force hospitals to develop business strategies to be competitive. Brand equity has a strategic role to create an advantage and distinction over other competitors. This study analyzes the effect of brand equity on brand loyalty at the hospital. The design used is cross-sectional involving 200 samples who were determined using a purposive sampling technique. The statistical test used was the $t$-test $(\alpha=0.05)$. The results showed that the overall variable brand awareness, preference metrics, financial metrics, output metrics, competitive metrics, local marketers' perception metrics affected brand loyalty. However, partially the variables of brand awareness and perceptions of local marketers did not have a positive effect. It is recommended that the hospital improves the ease of access and affordability of faciliti es for patients who use vehicles, provides discounts to patients, especially general/non-insured patients who have been treated repeatedly.
\end{abstract}

\begin{abstract}
ABSTRAK
Pertumbuhan rumah sakit yang pesat menciptakan kondisi yang memaksa rumah sakit untuk merumuskan strategi bisnis agar mampu bersaing. Ekuitas merek memiliki peran strategis untuk menciptakan keunggulan dan ciri khas dibanding kompetitor lainnya. Studi ini bertujuan menganalisis pengaruh ekuitas merek terhadap loyalitas merek di rumah sakit. Desain yang digunakan cross-sectional dengan melibatkan 200 orang sampel yang ditentukan menggunakan teknik purposive sampling. Uji statistik yang digunakan adalah uji t $(\alpha=0,05)$. Hasil penelitian menunjukkan bahwa secara keseluruhan variabel kesadaran merek, metrik preferensi, metrik keuangan, metrik keluaran, metrik kompetitif, metrik persepsi pemasar lokal berpengaruh pada loyality brand. Namun secara parsial variabel kesadaran merek dan persepsi pemasar lokal tidak berpengaruh positif. Direkomendasikan agar pihak rumah sakit meningkatkan kemudahan akses dan keterjangkauan fasilitas bagi pasien dan keluarganya yang menggunakan kendaraan, memberikan diskon kepada pasien, terutama pasien umum/non asuransi yang sudah berulang kali berobat.
\end{abstract}

\section{GRAPHICAL ABSTRACT}

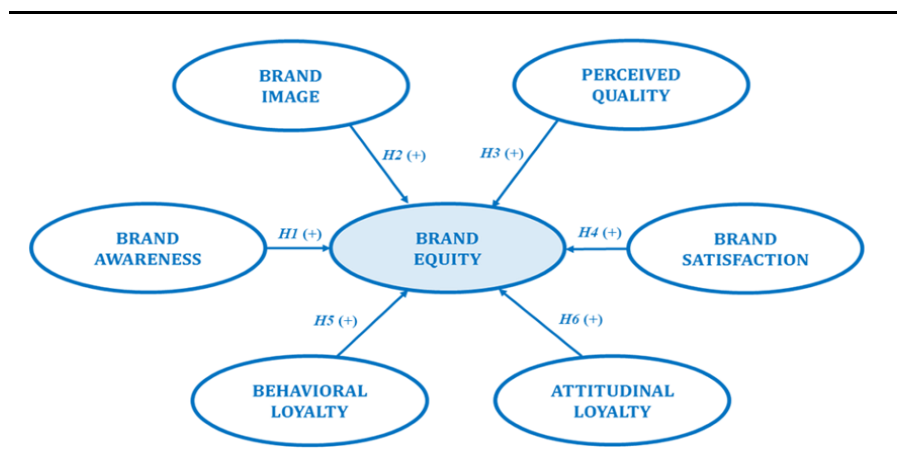

Keyword

brand equity; brand loyalty; hospital; patient loyalty

Kata Kunci:

ekuitas merek; loyalitas merek; loyalitas pasien; rumah sakit

\section{* Correspondence}

Jl. Pabrik Tenun No. 103, Kelurahan Sei Putih

Tengah, Kota Medan, 20118

Email:putrantomanalu@unprimdn.ac.id 


\section{PENDAHULUAN}

Rumah sakit sebagai pemberi layanan kesehatan diharuskan membangun merek yang kuat dari masa ke masa agar mampu bertahan di era persaingan antar rumah sakit yang cenderung berubah dengan cepat. Secara global, pertumbuhan rumah sakit sangat pesat dalam beberapa dekade terakhir. Di beberapa negara Eropa seperti Prancis pada tahun 2013 dilaporkan terdapat 3382 rumah sakit, di Jerman 3182, Ukraina 2156, Italia 1156, dan Polandia 1072 (WHO Regional Office for Europe, 2016). Sedangkan di Indonesia, data pertambahan jumlah rumah sakit dari tahun 2013 sampai tahun 2018 berturut-turut adalah 2083, 2228, 2404, 2490, 2601, 2773, dan 2820. Sejak tahun 2012, jumlah rumah sakit di Indonesia semakin meningkat dengan persentase pertumbuhan rata-rata 5.2\%. Jumlah rumah sakit swasta lebih banyak dibandingkan rumah sakit pemerintah dengan ratarata pertumbuhan sebesar $7 \%$. Sedangkan pertumbuhan rumah sakit pemerintah hanya sebesar 3\% (Trisnantoro \& Listyani, 2018). Situasi tersebut membuat persaingan antar rumah sakit semakin ketat dalam menarik minat pelanggan untuk memanfaatkan jasa layanan mereka. Identifikasi pada area yang berdampak signifikan pada kepuasan pasien perlu mempertimbangkan besaran biaya yang muncul tanpa mengorbankan kualitas layanan (Trinh \& Begun, 2019).

Rumah sakit dalam menjalankan bisnisnya tidak terlepas dari strategi pengembangan bisnis. Strategi yang dimaksudkan banyak dilakukan dengan memanfaatkan kekuatan dari brand perusahaan. Perluasan terhadap brand dapat dilihat dari dua sisi, yaitu sisi produsen (transferabilitas keahlian serta aset) dan sisi konsumen (komplementalitas dan substitusi) (Kotler \& Keller, 2016). Pada masa lalu, aspek pemasaran pada layanan kesehatan cenderung kurang menjadi fokus penting, padahal ekuitas merek memiliki peran strategis untuk menciptakan keunggulan dan ciri khas dibanding kompetitor lainnya (Yaghoubian et al., 2018). Selain itu, merek yang bagus akan sangat membantu manajemen dalam merekrut dan mempertahankan tenaga medis yang berkompeten (Yaghoubi et al., 2017).

Strategi manajemen sumber daya manusia yang efektif sangat dibutuhkan untuk mencapai hasil yang lebih baik dari dan ke akses perawatan kesehatan di seluruh dunia. Manajemen sumber daya manusia yang tepat sangat penting dalam memberikan perawatan kesehatan yang berkualitas tinggi (Kabene \& Beil-Hildebrand, 2011). Berbagai kajian menunjukkan peran penting sumber daya manusia pada penyedia layanan kesehatan karena berdampak pada kualitas layanan yang dirasakan oleh pasien. Hardavella et al. (2017) menyatakan pendekatan dan gaya komunikasi dokter akan mempengaruhi interaksi pasien dan dapat memiliki efek buruk yang serius pada pasien (misalnya jika tenaga kesehatan sombong atau tidak sabar dan percaya bahwa mereka tidak bertanggung jawab untuk mendiskusikan situasi dengan pasien atau menjelaskan kondisinya dengan cara yang dapat dipahami pasien. Oleh karena itu, penting untuk memiliki SDM yang kompeten agar pasien merasa puas dan pada akhirnya menjadi loyal. 
Studi kualitatif di Iran yang dilakukan Mosadeghrad (2014) memberikan kesimpulan bahwa institusi perawatan kesehatan harus memiliki sumber daya yang cukup untuk berinvestasi dalam kualitas layanan medis. Permasalahan seperti kekurangan staf berpengaruh pada waktu yang tersedia untuk pelayanan medis individu, dokter juga kewalahan dalam menghadapi pasien yang cukup banyak, serta ketersediaan alat dan bahan medis yang menunjang kinerja dokter. Pihak manajemen harus memiliki perhatian dan memberikan pendekatan khusus pada permasalahan tersebut agar mampu menghasilkan pelayan yang berkualitas yang pada akhirnya memberikan dampak pada citra rumah sakit dan loyalitas pasien. Implementasi JKN di Indonesia juga menghadapi masalah yang sama dalam ketersediaan dan kualitas SDM untuk menghadapi lonjakan permintaan layanan kesehatan. Kesigapan petugas dan jumlah yang memadai sangat diperlukan dalam menghadapi peningkatan kunjungan (Mujiati \& Yuniar, 2017). Mutu adalah salah satu faktor penentu citra rumah sakit di mata masyarakat. Dengan bergabungnya pihak swasta sebagai provider layanan kesehatan dalam JKN menuntut pihak manajemen untuk adaptasi dan menerapkan perencanaan strategis sesegera mungkin. Proses uji kelayakan yang dilakukan BPJS Kesehatan menuntut rumah sakit meningkatkan mutu pelayanan dengan pemenuhan persyaratan standar yang ditetapkan agar mampu menjadi sarana rujukan dari fasilitas kesehatan tingkat primer.

Merek sangat penting sehingga di- anggap sebagai ekuitas bagi perusahaan. Saat ini, konsumen tampaknya lebih sadar akan produk yang mereka beli, dan pada saat yang sama, produk dikembangkan dengan cara yang belum pernah ada sebelumnya (Wang et al., 2014). Ekuitas merek dalam perawatan kesehatan dibangun melalui akumulasi pikiran, perasaan, pendapat, dan perilaku yang berkelanjutan mengenai rumah sakit atau sistem kesehatan berdasarkan pengalaman yang diberikan kepada pelanggan. Ekuitas merek bisa melalui sharing antara pelanggan dengan keluarga dan kolega mengenai pelayanan yang diterimanya (Donohue, 2016). Studi terdahulu mengaitkan antara ekuitas merek dan citra merek rumah sakit. Studi di rumah sakit Salman Farsi Bushehr Iran menunjukkan bahwa kedua variabel tersebut berpengaruh positif dan signifikan. Citra merek, loyalitas merek, dan ekuitas merek dapat dibentuk dengan peningkatan benefit pelayanan yang dirasakan oleh pasien dan kemandirian dokter (Dalaki et al., 2019). Pemahaman ekuitas merek menjadi pendorong utama dalam mengkomunikasikan nilai kepada konsumen dan pengguna akhir. Peningkatan nilai merek didefinisikan sebagai ekuitas merek (Ebrahim, 2020; Sagynbekova et al., 2021).

Citra dan ekuitas merek juga dapat dibentuk dari kepercayaan, kepuasan, komitmen hubungan, loyalitas merek dan kesadaran merek. Pasien melihat layanan kesehatan sebagai layanan yang dapat memenuhi kebutuhan, sikap yang ramah, sopan santun, tepat waktu, tanggap, serta mampu menyembuhkan serta mencegah berkembangnya penyakit (Karbalaei et al., 
2013). Persepsi konsumen yang baik pada merek dapat membantu perusahaan dalam menonjolkan keunggulan kompetitif (Gupta et al., 2020). Pada studi lainnya, empat elemen ekuitas merek (brand awareness, perceived quality, brand association, brand loyalty) memiliki pengaruh yang signifikan dalam mendorong pemanfaatan pelayanan oleh pasien dan melakukan kunjungan di waktu mendatang (Asriani et al., 2019; Rivai et al., 2018). Studi Jeon (2017) menyimpulkan bahwa konsep merek berkontribusi penting terhadap ekuitas merek. Kinerja merek yang unggul seperti pangsa pasar yang lebih besar dapat dihasilkan dari komitmen pelanggan yang lebih besar.

Dari survei awal yang dilakukan oleh peneliti pada bulan Juli terhadap 10 pasien yang menggunakan layanan di Rumah Sakit Royal Prima Medan didapatkan jawaban yang beragam. Lima orang mengatakan alasannya karena lokasi yang dekat dengan tempat tinggal, 3 orang mengatakan karena rujukan dari layanan fasilitas kesehatan primer, dan 2 orang mengatakan karena fasilitas yang diberikan cukup nyaman bagi pasien. Hasil survei awal mengindikasikan bahwa alasan pasien datang sebagian besar karena letak geografis dari rumah sakit yang dapat dijangkau dan hanya sebagian kecil karena pengaruh dari layanan yang diberikan. Hal tersebut disebabkan banyaknya dan tingginya persaingan pemberian layanan kesehatan. Untuk meningkatkan lebih banyak kunjungan maka diperlukan adanya strategi-strategi dalam peningkatan citra rumah sakit. Penelitian ini bertujuan untuk menganalisis pengaruh ekuitas merek terhadap kesetiaan kunjungan pasien pada
Rumah Sakit Royal Prima Medan.

\section{METODE PENELITIAN}

Peneliti menggunakan metode kuantitatif dengan desain cross-sectional. Penelitian dilakukan di Rumah Sakit Royal Prima Medan pada bulan Juli 2020 hingga Oktober 2020. Populasi dalam studi ini adalah seluruh pelanggan/pasien BPJS atau asuransi yang datang berkunjung ke poliklinik rawat jalan dan menggunakan jasa layanan Rumah Sakit Royal Prima Medan selama 6 bulan terakhir (April 2020 - September 2020). Rumah Sakit Royal Prima Medan merupakan rumah sakit swasta tipe B yang juga menjadi fasilitas kesehatan tingkat lanjut (FKTL) yang memiliki angka rujukan cukup tinggi di kota Medan. Sebanyak 12.796 orang pasien tercatat melakukan kunjungan dalam 6 bulan terakhir (Oktober 2019-Maret 2020), baik pasien BPJS maupun pasien umum. Penentuan sampel menggunakan teknik purposive sampling dengan kriteria berupa pasien umum/asuransi yang telah atau pernah menggunakan layanan rawat jalan di Rumah Sakit Royal Prima Medan minimal 6 bulan terakhir serta dapat dan mampu mengisi lembar kuesioner sesuai kemampuan dan pengetahuan responden yaitu sebanyak 200 orang.

Dalam mengumpulkan data, peneliti menggunakan kuesioner yang terdiri dari 7 kuesioner dengan menggunakan skala Likert. Setiap kuesioner merupakan rangkaian pernyataan dari responden yang meliputi kesadaran merek, metrik preferensi, metrik keuangan, metrik keluaran, metrik kompetitif, metrik persepsi pemasaran lokal dan 
loyalitas merek. Selanjutnya total skor pada setiap kuesioner dikelompokkan menjadi beberapa kategori untuk mempermudah dalam melakukan tabulasi silang. Kategori tersebut antara lain baik, sedang, dan tidak baik. Peneliti juga melakukan uji validitas dan reliabilitas pada semua kuesioner yang disebarkan kepada responden dari rumah sakit yang berbeda dengan lokasi penelitian. Hasil uji menunjukkan bahwa seluruh kuesioner valid dengan melihat nilai Cronbach's alpha yang lebih besar dari konstanta $(0,6)$. Pengumpulan data juga dilakukan dengan studi dokumen dan pedoman observasi.

Untuk menjawab tujuan studi ini, peneliti melakukan uji statistik pada analisis bivariat dengan uji $t$ dengan ketentuan $\mathrm{H}_{0}$ ditolak dan $\mathrm{H}_{\mathrm{a}}$ diterima jika $t_{\text {hitung }} \geq \mathrm{t}_{\text {tabel. }}$ Tingkat signifikansi yang ditetapkan peneliti adalah sebesar 0,05 (5\%). Pada penyajian hasil penelitian, distribusi frekuensi responden disusun untuk melihat karakteristik responden yang terlibat dalam studi ini.

\section{HASIL PENELITIAN}

Penelitian ini bertujuan untuk menganalisis pengaruh ekuitas merek terhadap loyalitas merek di Rumah Sakit Royal Prima Medan. Sampel yang terlibat dalam studi ini sebanyak 200 pasien. Responden paling banyak adalah laki-laki $(58 \%)$ dan pada kategori umur terbanyak berusia $\leq 30$ tahun. Mayoritas pekerjaan responden adalah karyawan (50\%) (lihat tabel 1).

Peneliti selanjutnya melakukan analisis univariat pada data yang bersumber dari jawaban pada kuesioner yang telah dibagikan pada responden. Pada tabel 2 terlihat bahwa kelompok dengan kesadaran merek terbesar berada pada kategori sedang (84\%) dan yang terkecil ialah pada kategori baik (4\%). Kelompok dengan metrik prefensi terbesar berada pada kategori sedang $(80 \%)$ dan yang terkecil ialah pada kategori tidak baik (0\%). Kelompok dengan metrik keuangan terbesar berada pada kategori sedang $(61,5 \%)$ dan yang terkecil ialah pada kategori baik (0\%). Kelompok dengan metrik keluaran terbesar berada pada kategori sedang (70\%) dan yang terkecil ialah pada kategori baik (3,5\%). Metrik kompetitif terbesar berada pada kategori sedang $(84,5 \%)$ dan yang terkecil ialah pada kategori baik $(0 \%)$. Metrik persepsi pemasar lokal terbesar berada pada kategori sedang (57\%) dan yang terkecil ialah pada kategori tidak baik (4\%). Loyality brand terbesar berada pada kategori sedang (89\%) dan yang terkecil ialah pada kategori tidak baik (3,5\%). Hasil analisis univariat selengkapnya disajikan pada tabel 2 .

Pada tabel 3 terlihat bahwa seluruh variabel independen berpengaruh secara signifikan terhadap loyality brand. Seluruh nilai $\mathrm{p}<0,05$. Namun variabel kesadaran merek dan metrik persepsi pemasar lokal secara parsial tidak berpengaruh positif terhadap loyality brand. Hal ini terlihat dari nilai $\mathrm{t}$ masing-masing variabel tersebut sebesar $-4,751$ dan $-8,186$. Sedangkan hasil uji $t$ pada variabel metrik preferensi $\left(t_{\text {hitung }}=\right.$ 2,779 ), metrik keuangan ( $t_{\text {hitung }}=3,686$ ), metrik keluaran $\left(t_{\text {hitung }}=2,511\right)$, dan metrik kompetitif $\left(t_{\text {hitung }}=5,993\right)$ secara parsial 
Tabel 1

Karakteristik Responden

\begin{tabular}{lcc}
\hline & Variabel & \multicolumn{2}{c}{ Total Responden } \\
\cline { 2 - 3 } & $\mathrm{n}$ & $\%$ \\
\hline Jenis Kelamin & 116 & 58 \\
Laki-laki & 84 & 42 \\
$\quad$ Perempuan & & \\
Umur & 102 & 51 \\
$\quad \leq 30$ tahun & 98 & 49 \\
$\quad>30$ tahun & & \\
Pekerjaan & 46 & 23 \\
PNS & 46 & 23 \\
Wiraswasta & 50 & 25 \\
Karyawan & 30 & 15 \\
Lain-lain & & \\
\hline
\end{tabular}

berpengaruh positif terhadap loyality brand.

\section{PEMBAHASAN}

Studi ini berfokus mengukur pengaruh ekuitas merek (kesadaran merek, metrik preferensi, metrik keuangan, metrik keluaran, metrik kompetitif, metrik persepsi pemasaran lokal) terhadap loyality brand. Ekuitas merek telah menjadi bidang kajian yang cukup dikritisi dalam manajemen pemasaran sejak tahun 1990-an. Ekuitas merek muncul ketika konsumen bersedia membayar lebih untuk tingkat kualitas yang sama karena daya tarik nama yang melekat pada produk. Oleh karena itu penting untuk mengukur ekuitas merek dari perspektif konsumen (Yasin \& Aziz, 2013). Kesadaran merek dan komponen citra ekuitas merek membantu organisasi untuk secara efektif mentransfer nilai-nilai khas mereka kepada konsumen untuk membantu konsumen dalam mengambil keputusan untuk konsumsi barang atau jasa (Alam \& Khan, 2019; Koçyiğit \& Çakırkaya, 2019). Dalam studi ini yang menjadi objek penelitian adalah brand dari Rumah Sakit Royal Prima Medan, Sumatera Utara, Indonesia.
Dari hasil analisis didapatkan hasil bahwa variabel kesadaran merek berpengaruh secara signifikan terhadap loyality brand, hal ini terlihat dari taraf signifikansi $(0,000)<0,05$. Dengan nilai thitung sebesar -4,751 maka variabel kesadaran merek secara parsial tidak berpengaruh positif terhadap loyality brand. Sekalipun konsumen secara penuh sadar dan mengetahui tentang kualitas pelayanan dari Rumah Sakit Royal Prima namun hal tersebut tidak cukup untuk membuat seseorang menggunakan layanan yang ditawarkan. Hal tersebut terutama karena banyaknya kompetitor yang juga mungkin memberikan penawaran layanan dengan kualitas yang sama atau bahkan mungkin lebih baik. Hasil tinjauan naratif Angela \& Adisasmito (2019) menyimpulkan bahwa manajemen pelayanan kesehatan harus memperhatikan tidak hanya kualitas layanan kesehatan yang baik tetapi juga memenuhi kebutuhan pelanggan akan layanan kesehatan sehingga dapat membangun kepuasan dan loyalitas pasien yang lebih tinggi, serta meningkatkan pendapatan.

Konsumen juga cenderung melakukan konfirmasi terlebih dahulu baik dengan 
Tabel 2

Distribusi Frekuensi Jawaban Responden

\begin{tabular}{|c|c|c|}
\hline \multirow[t]{2}{*}{ Variabel } & \multicolumn{2}{|c|}{ Responden } \\
\hline & $\mathrm{n}$ & $\%$ \\
\hline \multicolumn{3}{|l|}{$\overline{\text { Kesadaran merek }}$} \\
\hline Baik & 8 & 4 \\
\hline Sedang & 168 & 84 \\
\hline Tidak Baik & 24 & 12 \\
\hline \multicolumn{3}{|l|}{ Metrik preferensi } \\
\hline Baik & 40 & 20 \\
\hline Sedang & 160 & 80 \\
\hline Tidak Baik & 0 & 0 \\
\hline \multicolumn{3}{|l|}{ Metrik keuangan } \\
\hline Baik & 0 & 0 \\
\hline Sedang & 123 & 61,5 \\
\hline Tidak Baik & 77 & 38,5 \\
\hline \multicolumn{3}{|l|}{ Metrik keluaran } \\
\hline Baik & 7 & 3,5 \\
\hline Sedang & 140 & 70 \\
\hline Tidak Baik & 53 & 26,5 \\
\hline \multicolumn{3}{|l|}{ Metrik kompetitif } \\
\hline Baik & 0 & 0 \\
\hline Sedang & 169 & 84,5 \\
\hline Tidak Baik & 31 & 15,5 \\
\hline \multicolumn{3}{|l|}{ Metrik persepsi pemasar lokal } \\
\hline Baik & 78 & 39 \\
\hline Sedang & 114 & 57 \\
\hline Tidak Baik & 8 & 4 \\
\hline \multicolumn{3}{|l|}{ Loyality Brand } \\
\hline Baik & 15 & 7,5 \\
\hline Sedang & 178 & 89 \\
\hline Tidak Baik & 7 & 3,5 \\
\hline
\end{tabular}

orang yang pernah menggunakan layanan ataupun si penyedia layanan itu sendiri. Pada studi ini variabel metrik persepsi pemasar lokal berpengaruh secara signifikan terhadap loyality brand, namun secara parsial tidak berpengaruh positif. Artinya meskipun rumah sakit telah melakukan promosi dengan baik, namun di lapangan konsumen akan lebih melihat perlakuan atau pelayanan yang didapatkan orang lain terlebih dahulu. Rekomendasi dari pengunjung sebelumnya melalui mulut ke mulut menjadi faktor penting dalam meningkatkan pengunjung baru $(\mathrm{Ng}$ et al.,
2011). Pihak manajemen perlu mempertimbangkan penggunaan media sosial dan pemantauan secara berkala pada respons yang diberikan pelanggan. Pelanggan lebih memilih membaca review dan rekomendasi pelanggan lain, karena akan lebih mudah bagi mereka untuk mengambil keputusan dalam membeli produk (Huarng, 2015).

Hasil analisis pada variabel metrik preferensi menunjukkan pengaruh signifikan pada loyality brand dan secara parsial berpengaruh positif. Responden beranggapan kemudahan akses ataupun lokasi strategis dari suatu rumah sakit menjadi alasan 
Tabel 3

Hasil Analisis Bivariat

\begin{tabular}{|c|c|c|c|c|c|c|c|c|}
\hline \multirow[t]{3}{*}{ Variabel } & \multicolumn{6}{|c|}{ Loyality Brand } & \multirow[t]{3}{*}{$t$} & \multirow[t]{3}{*}{ Sig } \\
\hline & \multicolumn{2}{|c|}{ Baik } & \multicolumn{2}{|c|}{ Sedang } & \multicolumn{2}{|c|}{ Tidak Baik } & & \\
\hline & $\mathrm{n}$ & $\%$ & $\mathrm{n}$ & $\%$ & $\mathrm{n}$ & $\%$ & & \\
\hline \multicolumn{9}{|l|}{ Kesadaran merek } \\
\hline Baik & - & - & 8 & 100 & - & - & & \\
\hline Sedang & 7 & 4 & 154 & 92 & 7 & 4 & $-4,571$ & 0,000 \\
\hline Tidak Baik & 8 & 33 & 16 & 67 & - & - & & \\
\hline \multicolumn{9}{|l|}{ Metrik preferensi } \\
\hline Baik & - & - & 40 & 100 & - & - & & \\
\hline Sedang & 15 & 9 & 138 & 87 & 7 & 4 & 2,779 & 0,006 \\
\hline Tidak Baik & - & - & - & - & - & - & & \\
\hline \multicolumn{9}{|l|}{ Metrik keuangan } \\
\hline Baik & - & - & - & - & - & - & & \\
\hline Sedang & 15 & 12 & 108 & 88 & - & - & 3,686 & 0,000 \\
\hline Tidak Baik & - & - & 70 & 90 & 7 & 10 & & \\
\hline \multicolumn{9}{|l|}{ Metrik keluaran } \\
\hline Baik & - & - & - & - & 7 & 100 & & \\
\hline Sedang & 15 & 11 & 125 & 89 & - & - & 2,511 & 0,013 \\
\hline Tidak baik & - & - & 53 & 100 & - & - & & \\
\hline \multicolumn{9}{|c|}{$\begin{array}{l}\text { Metrik persepsi pemasar } \\
\text { lokal }\end{array}$} \\
\hline Baik & - & - & 78 & 100 & - & - & & \\
\hline Sedang & 7 & 6 & 100 & 88 & 7 & 6 & $-8,186$ & 0,000 \\
\hline Tidak Baik & 8 & 100 & - & - & - & - & & \\
\hline \multicolumn{9}{|l|}{ Metrik kompetitif } \\
\hline Baik & - & - & - & - & - & - & & \\
\hline Sedang & 15 & 9 & 147 & 87 & 7 & 4 & 5,993 & 0,000 \\
\hline Tidak Baik & - & - & 31 & 100 & - & - & & \\
\hline
\end{tabular}

kuat. Mengingat banyaknya penyedia pelayanan rawat jalan terutama rumah sakit swasta akan membuat tiap-tiap rumah sakit akan saling berlomba-lomba untuk menawarkan pelayanan yang berkualitas. Ketika penawaran tiap rumah sakit berada pada tingkatan menarik yang sama, maka tentunya lokasi yang strategis serta kemudahan akses akan menjadi salah satu faktor penentu yang akan membuat konsumen untuk mempertimbangkan lokasi yang paling dekat dan mudah untuk dijangkau dari tempat tinggal konsumen tersebut. Survei Dixon (2010) di Inggris menunjukkan pasien lebih memilih rumah sakit yang dekat dengan rumah atau tempat kerja mereka. Jarak men- jadi pertimbangan penting bagi mereka yang berpenghasilan rendah atau mereka yang bergantung pada transportasi rumah sakit (Smith et al., 2018). Studi menunjukkan bahwa waktu tempuh merupakan determinan terpenting dalam pemilihan pasien di rumah sakit. Akreditasi rumah sakit dan waktu tunggu juga memiliki dampak yang signifikan terhadap pilihan rumah sakit pasien (Beukers et al., 2014). Rumah sakit dengan saingan yang cukup banyak perlu memperhatikan kualitas pelayanan dan waktu tunggu agar mampu bersaing (Moscelli et al., 2016). Sementara itu umumnya minat beli ulang muncul ketika konsumen memiliki preferensi pribadi ke 
arah merek atau produk tertentu pada waktu yang lalu yang kemudian menjadi pemicu untuk mengulang preferensinya tersebut (Verdilla \& Albari, 2018). Kepribadian konsumen turut berpengaruh terhadap loyalitas, yang mana kepribadian itu berhubungan dengan preferensi serta penggunaan (Novita \& Lubis, 2018).

Keuangan menjadi salah satu faktor yang dianalisis dalam penelitian ini, di mana hasil uji statistik menunjukkan variabel metrik keuangan berpengaruh secara signifikan terhadap loyality brand dan secara parsial berpengaruh positif. Tanpa adanya asuransi ataupun jaminan kesehatan, biaya penggunaan layanan kesehatan terutama di rumah sakit swasta tergolong cukup besar. Faktor tersebut tentunya menyebabkan seseorang akan berpikir 2 kali untuk menggunakan suatu layanan kesehatan terutama bila biaya yang dibutuhkan cukup besar dibandingkan dengan rumah sakit lain. Studi Mosadeghrad (2014) menyimpulkan biaya pelayanan menjadi alasan utama pemilihan rumah sakit oleh pasien di Iran. Rumah sakit yang berafiliasi dengan jaminan sosial kesehatan menjadi pilihan utama pasien. Pasien percaya bahwa kualitas pelayanan di rumah sakit swasta lebih baik daripada rumah sakit umum. Namun, beberapa pasien menyatakan bahwa pelayanan rumah sakit swasta terlalu mahal bagi mereka. Lebih dari tiga perempat pasien rawat inap di rumah sakit swasta menegaskan rekomendasi dokter sebagai alasan mereka memilih rumah sakit tersebut. Perlindungan asuransi adalah alasan utama pilihan pasien rawat jalan di rumah sakit swasta. Sementara itu, di Indonesia telah banyak rumah sakit milik pemerintah dan swasta yang bekerja sama dengan BPJS Kesehatan sebagai penyelenggara Jaminan Kesehatan Nasional. Kepemilikan jaminan kesehatan meningkatkan akses layanan rawat inap sebesar $115,8 \%$ dan terbukti mampu mempersempit kesenjangan layanan rawat inap di rumah sakit (Nugraheni \& Hartono, 2017). Namun penelitian menyimpulkan implementasi program JKN juga berdampak pada tingkat efisiensi rumah sakit. Keterlambatan pembayaran klaim oleh BPJS Kesehatan serta besaran tarif INA-CBGs yang dianggap belum rasional adalah faktor pemicu inefisiensi tersebut (Irwandy \& Sjaaf, 2018). Sementara itu penelitian Prasetya \& Suhita (2019) menunjukkan bahwa tarif atau harga bukanlah satu-satunya pertimbangan dalam memilih layanan kesehatan. Nilai, layanan, produk ataupun kualitas menjadi faktor lain yang menjadi pertimbangan pasien.

Komponen lain dari ekuitas merek yang diteliti pada studi ini adalah variabel metrik keluaran yang berpengaruh secara signifikan terhadap loyality brand dan secara parsial berpengaruh positif. Keluaran (output) dimaksudkan sebagai aktivitas pemasaran yang terukur. Pihak rumah sakit secara berkelanjutan perlu untuk terus melakukan promosi melalui berbagai media guna memperluas jangkauan informasi dan menjaring pelanggan baru. Menurut Bendle et al. (2016) efektivitas pemasaran tergantung pada tujuan perusahaan. Karena meningkatnya permintaan akan pengetahuan pemasar, perlu untuk fokus pada kerangka kerja yang memungkinkan untuk mengukur dampak keuangan 
jangka pendek dan jangka panjang pada investasi pemasaran perusahaan. Mengukur kinerja pemasaran merupakan proses yang penting dilakukan untuk mendapatkan umpan balik kinerja atas hasil kegiatan pemasaran. Sementara itu, variabel metrik kompetitif juga berpengaruh signifikan terhadap loyality brand, dan secara parsial berpengaruh positif. Variabel ini berfokus pada bagaimana rumah sakit harus bisa memberikan penawaran dan pelayanan terbaik dibandingkan kompetitor lain, yang artinya semakin baik penawaran dan pelayanan yang diberikan maka akan semakin tinggi juga peluang seseorang menggunakan layanan rumah sakit tersebut ketimbang kompetitornya. Wu (2014) menyatakan persaingan dalam kualitas merupakan kunci penting dalam peningkatan jumlah dan pendapatan rumah sakit, dan pada akhirnya membangun daya kompetitif dengan rumah sakit lain. Kepemimpinan dan budaya rumah sakit dapat menjadi faktor yang mendorong dan membentuk strategi kompetitif rumah sakit dan hasil kinerja terkait. Penelitian Susanti \& Wardana (2015) menyebutkan bahwa perusahaan harus mengembangkan strategi diferensiasi untuk memperoleh keunggulan kompetitif yang mana memiliki hubungan dengan loyalitas pelanggan.

\section{KESIMPULAN}

Penelitian ini menyimpulkan bahwa secara keseluruhan variabel kesadaran merek, metrik preferensi, metrik keuangan, metrik keluaran, metrik kompetitif, metrik persepsi pemasar lokal berpengaruh pada loyality brand. Namun secara parsial varia- bel kesadaran merek dan persepsi pemasar lokal tidak berpengaruh positif. Pengukuran faktor-faktor yang berimplikasi pada loyalitas pasien masih cukup relevan mengingat persaingan pada pasar pelayanan kesehatan yang cukup kompetitif. Kualitas pelayanan yang optimal yang diberikan rumah sakit pada akhirnya meningkatkan loyalitas pasien atau minat berkunjung ulang. Studi ini hanya melibatkan satu rumah sakit saja dan tidak menelaah strategi-strategi yang dikembangkan pihak manajemen dalam menaikkan citra rumah sakit. Direkomendasikan pada peneliti selanjutnya untuk menganalisis secara kualitatif strategistrategi yang dijalankan pihak manajemen dalam upaya mempertahankan pelanggan lama dan menarik pelanggan baru.

Disarankan agar pihak rumah sakit meningkatkan kemudahan akses bagi pasien-pasien yang menggunakan kendaraan, memberikan diskon kepada pasien, terutama pasien umum/non asuransi, yang sudah berulang kali berobat. Selain itu pelatihan berkesinambungan kepada dokter, perawat, bidan ataupun paramedis lainnya perlu diadakan dengan tujuan peningkatan kualitas dan kompetensi SDM

\section{DAFTAR PUSTAKA}

Alam, M. S., \& Khan, B. (2019). The Role of Social Media Communication in Brand Equity Creation: An Empirical Study. The IUP Journal of Brand Management: IJBRM, 16(1), 54-78. https://www.proquest.com/openview/72e3376 b5d11e03272f0907cbe5de378/

Angela, N., \& Adisasmito, W. B. B. (2019). Brand Equity and Customer's Loyalty in Healthcare Setting: A Narrative Review. JMJ, 7(2), 190199. https://onlinejournal.unja.ac.id/kedokteran/article/view/8027 
Asriani, I., Usman, \& Majid, M. (2019). Pengaruh Ekuitas Merek Terhadap Keputusan Pemanfaatan Pelayanan Rawat Jalan Rumah Sakit Ibu Dan Anak Ananda Trifa Kota Parepare. Jurnal Ilmiah Manusia Dan Kesehatan, 2(3), 354-366.

https://doi.org/10.31850/makes.v2i3.178

Bendle, N. T., Farris, P. W., Pfeifer, P. E., \& Reibstein, D. J. (2016). Marketing metrics: The Definitive guide to measuring marketing performance (3rd ed.). Pearson Education.

Beukers, P. D. C., Kemp, R. G. M., \& Varkevisser, M. (2014). Patient hospital choice for hip replacement: empirical evidence from the Netherlands. The European Journal of Health Economics, 15(9), 927-936. https://doi.org/10.1007/s10198-013-0535-7

Dalaki, F., Esmaeilpour, M., \& Bahrainizad, M. (2019). Explaining Factors Affecting Brand Image of Hospital with the Emphasis on Branding in Health Services Marketing; Case Study of Salman-e Farsi Hospital in Bushehr. Health Research Journal, 4(2), 63-71. https://doi.org/10.29252/hrjbaq.4.2.63

Donohue, R. (2016). Brand Equity In Healthcare: The Impact Of Branding In A Changing Healthcare Landscape. https://nrchealth.com/wpcontent/uploads/2016/10/Brand-Equity-CaseStudy.pdf

Ebrahim, R. S. (2020). The Role of Trust in Understanding the Impact of Social Media Marketing on Brand Equity and Brand Loyalty. Journal of Relationship Marketing, 19(4), 287308.

https://doi.org/10.1080/15332667.2019.17057 42

Gupta, S., Gallear, D., Rudd, J., \& Foroudi, P. (2020). The impact of brand value on brand competitiveness. Journal of Business Research, 112(March), 210-222. https://doi.org/10.1016/j.jbusres.2020.02.033

Hardavella, G., Aamli-Gaagnat, A., Frille, A., Saad, N., Niculescu, A., \& Powell, P. (2017). Top tips to deal with challenging situations: Doctor-patient interactions. Breathe, 13(2), 129135.

https://doi.org/10.1183/20734735.006616

Huarng, K.-H. (2015). Configural theory for ICT development. Journal of Business Research, 68(4),

748-756. https://doi.org/https://doi.org/10.1016/j.jbusre s.2014.11.023

Irwandy, \& Sjaaf, A. C. (2018). Dampak Kebijakan Jaminan Kesehatan Nasional terhadap Efisiensi Rumah Sakit: Studi Kasus di Provinsi Sulawesi Selatan. Media Kesehatan Masyarakat Indonesia, 14(4), 360. https://doi.org/10.30597/mkmi.v14i4.5144

Jeon, J.-E. (2017). The impact of brand concept on brand equity. Asia Pacific Journal of Innovation and Entrepreneurship, 11(2), 233-245. https://doi.org/10.1108/apjie-08-2017-030

Kabene, S. M., \& Beil-Hildebrand, M. B. (2011). Re-Theorizing Human Resource Management and Human Resource Management in Context. In Human Resources in Healthcare, Health Informatics and Healthcare Systems (pp. 21-46). https://doi.org/10.4018/978-161520-885-2.ch002

Karbalaei, M., Abdi, A., Malmir, R., Dehghanan, H., Pirnejad, S., \& Jafari, S. (2013). Investigating of Brand Equity on Hospital Image. Research Journal of Applied Sciences, Engineering and Technology, 6, 3888-3894. https://doi.org/10.19026/rjaset.6.3606

Koçyiğit, M., \& Çakırkaya, M. (2019). Investigation of the Relationship Between Social Media Communication and Consumer Based Brand Equity: Consumer Research on a GSM Brand. Journal of Business Research - Turk, 11, 2027-2039.

https://doi.org/10.20491/isarder.2019.722

Kotler, P., \& Keller, K. L. (2016). Marketing Management (15th ed.). Pearson.

Mosadeghrad, A. M. (2014a). Factors affecting medical service quality. Iranian Journal of Public Health, 43(2), 210-220. https://www.ncbi.nlm.nih.gov/pmc/articles/P MC4450689/

Mosadeghrad, A. M. (2014b). Patient choice of a hospital: Implications for health policy and management. International Journal of Health Care Quality Assurance, 27(2), 152-164. https://doi.org/10.1108/IJHCQA-11-20120119

Moscelli, G., Siciliani, L., Gutacker, N., \& Gravelle, H. (2016). Location, quality and choice of hospital: Evidence from England 2002-2013. Regional Science and Urban Economics, 60, 112-124. https://doi.org/10.1016/j.regsciurbeco.2016.07 
.001

Mujiati, \& Yuniar, Y. (2017). Ketersediaan Sumber Daya Manusia Kesehatan pada Fasilitas Kesehatan Tingkat Pertama dalam Era Jaminan Kesehatan Nasional di Delapan KabupatenKota di Indonesia. Media Penelitian Dan Pengembangan Kesehatan, 26(4), 201-210. https://doi.org/10.22435/mpk.v26i4.4827.201210

Ng, S., David, M. E., \& Dagger, T. S. (2011). Generating positive word-of-mouth in the service experience. Managing Service Quality, 21(2), 133-151.

https://doi.org/10.1108/09604521111113438

Novita, P., \& Lubis, A. R. (2018). Pengaruh Kepribadian Terhadap Loyalitas Dengan Persepsi Kualitas Merek Dan Niat Beli Sebagai Variabel Mediasi (Studi Pada Retailer Showroom Mobil Toyota Di Banda Aceh). Jurnal Ilmiah Mahasiswa Ekonomi Manajemen, 3(2), 148-161.

https://doi.org/https://doi.org/10.24815/jimen.v $3 \mathrm{i} 2.7224$

Nugraheni, W. P., \& Hartono, R. K. (2017). Analisis Pola Layanan Kesehatan Rawat Jalan pada Tahun Pertama Implementasi Program Jaminan Kesehatan Nasional (JKN). Media Penelitian Dan Pengembangan Kesehatan, 27(1).

https://doi.org/10.22435/mpk.v27i1.6000.9-16

Prasetya, M. E., \& Suhita, B. M. (2019). Mutu Pelayanan dan Tarif Pelayanan Terhadap Minat Pemanfaatan Ulang Jasa Rawat Inap di Rumah Sakit Mardi Mulya Trenggalek. Journal of Chemical Information and Modeling, 53(9), 1689-1699.

https://www.sjik.org/index.php/sjik/article/vie w/139

Rivai, F., Amiruddin, R., Sumarni, \& Palutturi, S. (2018). Brand equity effect on service reutilization interest of inpatient installation of Ibnu Sina Hospital, Makassar in 2015. ACM International Conference Proceeding Series, 30(1), 213-222.

https://doi.org/10.1145/3242789.3242807

Sagynbekova, S., Ince, E., Ogunmokun, O. A., Olaoke, R. O., \& Ukeje, U. E. (2021). Social media communication and higher education brand equity: The mediating role of eWOM. Journal of Public Affairs, 21(1), e2112. https://doi.org/https://doi.org/10.1002/pa.2112
Smith, H., Currie, C., Chaiwuttisak, P., \& Kyprianou, A. (2018). Patient choice modelling: how do patients choose their hospitals? Health Care Management Science, 21(2), 259-268. https://doi.org/10.1007/s10729-017-9399-1

Susanti, N. P. H., \& Wardana, I. M. (2015). Pengaruh Kualitas Produk dan Citra Merek terhadap Kepuasan dan Loyalitas Pelanggan pada Produk Kosmetik Hijau Merek The Body Shop. E-Jurnal Manajemen Universitas Udayana, 4(2). https://ojs.unud.ac.id/index.php/Manajemen/art icle/view/11110

Trinh, H. Q., \& Begun, J. W. (2019). Strategic Differentiation of High-Tech Services in Local Hospital Markets. Inquiry (United States), 56. https://doi.org/10.1177/0046958019882591

Trisnantoro, L., \& Listyani, E. (2018). Jumlah RS di Indonesia: Pertumbuhan RS Publik. http://sirs.yankes.kemkes.go.id/rsonline/report/

Verdilla, V., \& Albari, A. (2018). Dampak Dimensi Ekuitas Merek Dalam Membentuk Minat Beli Ulang. Jurnal Manajemen Maranatha, 17(2), 81. https://doi.org/10.28932/jmm.v17i2.802

Wang, L., Dai, W., Addei-Duah, B., \& Wang, X. (2014). The literature review of brand equity and consumer buying behaviour: $1980 \square 2014$. 2014 International Conference on Mechatronics, Electronic, Industrial and Control Engineering, MEIC 2014, Meic, 1577-1581. https://doi.org/10.2991/meic-14.2014.349

WHO Regional Office for Europe. (2016). European Health Information Gateway: Total of Hospitals.

https:/gateway.euro.who.int/en/indicators/hlth res_78-hospitals-total/

Wu, W. (2014). Hospital Competitive Strategies and Performance Outcomes (University of Tennessee).

https://trace.tennessee.edu/utk_graddiss/2875/

Yaghoubi, M., Rafiei, S., Alikhani, M., \& Khosravizadeh, O. (2017). Modeling the brand loyalty of medical services in Iran's Military Hospitals. Annals of Tropical Medicine and Public Health, $10(4), \quad 841$. https://doi.org/10.4103/ATMPH.ATMPH_137 $-17$

Yaghoubian, S., Jahani, M. A., Yazdani-Charati, J., \& Mahmoudi, G. (2018). The role of marketing mix (the 7 Ps) in patients' attitudes to Iranian hospitals based on their kind of ownership 
(case study in Iran). International Journal of Healthcare Management, 11(4), 1-5. https://doi.org/10.1080/20479700.2018.150522 6

Yasin, N. M., \& Aziz, N. A. (2013). Determinants of Brand Equity of Services: A Verification Approach in the Banking Industry in Malaysia. ASEAN Marketing Journal, 2(2), 27-34. https://doi.org/10.21002/amj.v2i2.1998 